\title{
Liquid biopsy posttreatment surveillance in endemic nasopharyngeal carcinoma: a cost-effective strategy to integrate circulating cell-free Epstein-Barr virus DNA
}

Chen-Fei Wu' ${ }^{1 \dagger}$, Li Lin ${ }^{1 \dagger}$, Yan-Ping Mao ${ }^{1 \dagger}$, Bin Deng ${ }^{2 \dagger}$, Jia-Wei Lv' ${ }^{1}$ Wei-Hong Zheng ${ }^{1}$, Dan-Wan Wen', Jia Kou', Fo-Ping Chen ${ }^{1}$, Xing-Li Yang ${ }^{1}$, Si-Si Xu' ${ }^{1}$, Jun Ma', Guan-Qun Zhou ${ }^{1 *}$ and Ying Sun ${ }^{1 *}$

\begin{abstract}
Background: The optimal posttreatment surveillance strategy for nasopharyngeal carcinoma (NPC) remains unclear. Circulating cell-free Epstein-Barr virus (cfEBV) DNA has been recognized as a promising biomarker to facilitate early detection of NPC recurrence. Therefore, we aim to determine whether integrating circulating cfEBV DNA into NPC follow-up is cost-effective.

Methods: For each stage of asymptomatic nonmetastatic NPC patients after complete remission to primary NPC treatment, we developed a Markov model to compare the cost-effectiveness of the following surveillance strategies: routine follow-up strategy, i.e., (1) routine clinical physical examination; routine imaging strategies, including (2) routine magnetic resonance imaging plus computed tomography plus bone scintigraphy (MRI + CT + BS); and (3) routine ${ }^{18}$ F-fluorodeoxyglucose positron emission tomography/computed tomography (PET/CT); cfEBV DNA-guided imaging strategies, including (4) cfEBV DNA-guided MRI + CT + BS and (5) cfEBV DNA-guided PET/CT. Clinical probabilities, utilities, and costs were derived from published studies or databases. Sensitivity analyses were performed.

Results: For all disease stages, cfEBV DNA-guided imaging strategies demonstrated similar survival benefits but were considerably more economical than routine imaging strategies. They only required approximately one quarter of the number of imaging studies compared with routine imaging strategies to detect one recurrence. Specifically, cfEBV DNA-guided MRI + CT + BS was most cost-effective for stage II (incremental cost-effectiveness ratio [ICER] $\$ 57,308 /$ quality-adjusted life-year [QALY]) and stage III (\$46,860/QALY) patients, while cfEBV DNA-guided PET/CT was most cost-effective for stage IV patients $(\$ 62,269 / \mathrm{QALY})$. However, routine follow-up was adequate for stage I patients due to their low recurrence risk.
\end{abstract}

\footnotetext{
* Correspondence: zhougq@sysucc.org.cn; sunying@sysucc.org.cn

${ }^{+}$Chen-Fei Wu, Li Lin, Yan-Ping Mao and Bin Deng contributed equally to this work.

'Department of Radiation Oncology, Sun Yat-sen University Cancer Center; State Key Laboratory of Oncology in South China, Collaborative Innovation Center for Cancer Medicine, Guangdong Key Laboratory of Nasopharyngeal Carcinoma Diagnosis and Therapy, 651 Dongfeng Road East, Guangzhou 510060, Guangdong, People's Republic of China

Full list of author information is available at the end of the article
}

(c) The Author(s). 2021 Open Access This article is licensed under a Creative Commons Attribution 4.0 International License, which permits use, sharing, adaptation, distribution and reproduction in any medium or format, as long as you give appropriate credit to the original author(s) and the source, provide a link to the Creative Commons licence, and indicate if changes were made. The images or other third party material in this article are included in the article's Creative Commons licence, unless indicated otherwise in a credit line to the material. If material is not included in the article's Creative Commons licence and your intended use is not permitted by statutory regulation or exceeds the permitted use, you will need to obtain permission directly from the copyright holder. To view a copy of this licence, visit http://creativecommons.org/licenses/by/4.0/ The Creative Commons Public Domain Dedication waiver (http://creativecommons.org/publicdomain/zero/1.0/) applies to the data made available in this article, unless otherwise stated in a credit line to the data. 
Conclusions: The cfEBV DNA-guided imaging strategies are effective and cost-effective follow-up methods in NPC. These liquid biopsy-based strategies offer evidence-based, stage-specific surveillance modalities for clinicians and reduce disease burden for patients.

Keywords: Liquid biopsy, Circulating cell-free Epstein-Barr virus DNA, Posttreatment surveillance, Surveillance imaging, Cost-effectiveness, Nasopharyngeal carcinoma

\section{Background}

More than $20 \%$ of patients with nonmetastatic nasopharyngeal carcinoma (NPC) will experience disease recurrence despite aggressive primary treatment, contributing largely to treatment failure and death $[1,2]$. The posttreatment surveillance is essential to detect recurrence timely when the tumor burden is minimal, which would maximize the efficacy of salvage treatment and might improve survival [3-6]. However, surveillance can be challenging in NPC, and there is no consensus on the optimal follow-up modalities. Consequently, practice varies widely across clinicians and institutions. Although routine surveillance imaging, e.g., routine magnetic resonance imaging (MRI) and computed tomography (CT), is efficacious in detecting recurrence, it has been questioned due to the prohibitive resource consumption and economic burden [7]. Hence, it is imperative to identify a follow-up strategy that can detect recurrence in a timely and cost-effective manner.

Epstein-Barr virus (EBV) infections were predominant in endemic NPC [8]. Circulating cell-free EBV (cfEBV) DNA, short DNA fragments released by NPC cells, has been established as an NPC biomarker in population screening [9], risk assessment $[8,10]$, treatment evaluation [11, 12], and follow-up [13-16]. Several studies have shown that the posttreatment cfEBV DNA tests could facilitate early detection of NPC recurrence, especially for distant recurrence [13-18]. Specifically, detectable plasma cfEBV DNA during follow-up indicates tumor recurrence, while undetectable cfEBV DNA demonstrates continuous remission $[15,16,18]$. A recent work involving 1984 nonmetastatic NPC patients demonstrated that the sensitivity and specificity for cfEBV DNA to detect recurrence were up to 82.3 and $80.0 \%$, respectively, highlighting the efficacy of cfEBV DNA surveillance [16]. Another study investigating cfEBV DNA surveillance followed by positron emission tomography/ computed tomography (PET/CT) indicated that such strategy could correctly identify NPC recurrence while saved approximately four-fifths in expenses [14]. Therefore, the updated European Society for Medical Oncology (ESMO) guideline for NPC has recognized cfEBV DNA as a promising biomarker for recurrence and recommended evaluating it at least every year [17], and the National Comprehensive Cancer Network (NCCN) guidelines also suggested EBV DNA monitoring for NPC
[19]. However, little evidence is available regarding how to integrate cfEBV DNA into the current surveillance series $[14,17]$.

Considering that cfEBV DNA could promptly suggest disease recurrence with high accuracy [14-16], we proposed a liquid biopsy-based stepwise surveillance strategy, starting with routine cfEBV DNA tests, followed by further imaging studies if the tests are positive. We estimated its cost-effectiveness and compared it with other surveillance strategies in each stage of NPC. We speculated that selected imaging studies for patients with positive cfEBV DNA was a cost-effective follow-up modality, demonstrating the potential application of circulating cell-free DNA in the follow-up of cancer survivors. We aimed to establish evidence-based, stage-specific NPC surveillance strategies and investigate the potential application of circulating cell-free DNA in the follow-up of cancer survivors.

\section{Methods \\ Model construction}

We developed a Markov decision-analytic model to evaluate the cost-effectiveness of five surveillance strategies in NPC (Additional file 1: Fig. S1A): routine follow-up strategy, i.e., (1) routine clinical physical examination; routine imaging strategies, including (2) routine MRI plus CT plus bone scintigraphy (MRI + CT + BS); and (3) routine ${ }^{18} \mathrm{~F}$-fluorodeoxyglucose PET/CT; cfEBV DNA-guided imaging strategies, including (4) cfEBV DNA-guided MRI + CT + BS; and (5) cfEBV DNA-guided PET/CT. The routine follow-up included history and physical examinations, complete blood counts, comprehensive metabolic panels, and nasopharyngoscopies. The routine imaging strategies included routine follow-up and imaging studies. The cfEBV DNA-guided imaging strategies included routine followup and cfEBV DNA tests, whose positive results would trigger further imaging studies. MRI imaged the head and neck; CT imaged the chest and abdomen; BS imaged the whole body; and PET/CT imaged from the skull base to midthigh. According to the previous study [20], the surveillance was scheduled as follows: (1) stage I: 2 follow-up visits in year 1; 3 visits in year 2; 2 visits in year 3 and 4; and 1 visit in year 5, (2) stage II: 2 visits in year 1; 4 visits in year 2; 2 visits in year 3 and 4; and 1 visit in year 5, (3) stage III: 4 visits in year 1 and 2; 3 
visits in year 3; and 1 visit in year 4 and 5 , and (4) stage IV: 4 visits in year $1 ; 5$ visits in year 2; 3 visits in year 3; and 1 visit in year 4 and 5 . We chose a 5 -year follow-up duration because more than $90 \%$ of recurrence happened within this interval $[21,22]$.

We simulated the natural history of four hypothetical cohorts of 45-year-old asymptomatic nonmetastatic NPC patients with stage I, II, III, and IV disease after complete remission (CR) to the primary treatment. In each cohort, patients would move through the following health states: no evidence of disease (NED) after primary treatment, early- and advanced-stage recurrence (local relapse [LR], regional relapse [RR], or distant metastasis $[D M])$, salvage treatment for recurrence, NED after salvage treatment, and death (Additional file 1: Fig. S1B). In each 1-month cycle, the Markov model would accrue the costs and utilities as patients experienced different health states or events in a lifetime horizon. All future costs and utilities were discounted at a standard rate of $3 \%$ annually [23].

The primary outcomes included the cost, effectiveness, incremental cost-effectiveness ratio (ICER), and net health benefit (NHB) of each strategy. The ICER was defined as the incremental cost for an additional qualityadjusted life-year (QALY) gained by comparing two strategies. The willingness-to-pay threshold was set at $\$ 100,000 /$ QALY [24, 25]. Strategies with ICERs less than this threshold were considered cost-effective. The NHB, which is explicit and robust when comparing multiple strategies, was calculated with the formula: effectiveness-cost/willingness-to-pay [26]. The strategy with the highest NHB was considered the most cost-effective at the given willingness-to-pay threshold. Additionally, we compared the average number of imaging studies required to detect one disease recurrence among the different surveillance strategies.

All analyses were conducted and reported in line with the recommendations of the Second Panel on CostEffectiveness in Health and Medicine and the Consolidated Health Economic Evaluation Reporting Standards $[23,27]$. The institutional ethics committee approved the study and waived the requirement for informed consent given its retrospective nature (B2020-410). Tests were two-sided, and $P<0.05$ was defined as statistically significant. The Markov model was constructed in TreeAge Pro (TreeAge Software, Williamstown, MA), and other statistical analyses were performed using $\mathrm{R}$ (version 3.6.1, http://www.r-project.org).

\section{Model clinical estimates}

The base-case estimates are presented in Additional file 1: Table S1 [3, 4, 16, 20, 23, 28-56]. Monthly LR, RR, and DM probabilities were fitted by parametric survival models using the patient-level real-world data of an
NPC cohort containing 10,097 nonmetastatic NPC patients (median follow-up time, 67.3 months) collected from the NPC-specific database in our institution; detailed information about the cohort and the database are presented in Additional file 1: Table S2 and Additional file 2: Supplementary Methods [38, 57-62]. The fitness of exponential, Gompertz, log-logistic, log-normal, and Weibull distributions were evaluated [63]. Specifically, the log-normal distribution was applied to the LR data, while the Gompertz distribution was applied to the RR and DM data, as they demonstrated the best fit based on the Akaike information criterion [63, 64]. The agespecific background mortality rate was generated from the China life table (Additional file 1: Table S3) [46]. The starting age of 45 in the base-case analysis was the median age of the 10,097 patients. We assumed that undetected early-stage LR, RR, and DM had monthly probabilities of $10 \%, 10 \%$, and $20 \%$, respectively, to progress to advanced-stage recurrence based on the values utilized in a published study [20]. Other probabilities and clinical utilities for different health states were derived from published studies and, in few cases, from expert opinion if published data were unavailable (Additional file 1: Table S1). The literature search and data extraction are detailed in Additional file 2: Supplementary Methods. All transition probabilities were transformed into monthly scales via the declining exponential approximation of life-expectancy equation: $\mu=-1 / t \times$ $\ln (\mathrm{S})[65,66]$.

\section{Model validation}

To evaluate the ability of the Markov model to accurately describe the disease processes of NPC, we validated the model in two aspects. First, we compared the model-simulated disease recurrence patterns (LR, $R R$, and $D M$ ) against the real-world recurrence patterns in the NPC cohort of 10,097 patients. The model-simulated recurrence was generated from the Markov model using the base-case parameters, while the real-world recurrence was calculated using the Kaplan-Meier method. Second, we compared the model-predicted overall survival under the five surveillance strategies in this study with the real-world observed overall survival in the NPC cohort (KaplanMeier method). Although the patients in real-world clinical practice might be prescribed various follow-up modalities and intervals different from this study, the similarity between the model-predicted and observed survival could partially confirm the model's ability to reproduce the natural history of NPC patients because the recurrence patterns in the model were supposed to be similar to those in the real-world cohort. To better mimic the real-world circumstance consisting of various follow-up methods, we calculated the 
model-predicted overall survival using the average of the overall survival of the five surveillance strategies in the model.

\section{Costs}

Costs were derived from the 2019 Medical Insurance Administration Bureau of Guangzhou, China, or published studies from the societal perspective (Additional file 1: Table S1). Direct medical costs included costs of follow-up and salvage treatment. The costs assigned to a false-positive cfEBV DNA test or routine follow-up included the costs of additional imaging studies, while those assigned to a false-positive imaging study included the costs of nasopharyngoscopy- or CT-guided biopsy, pre-procedure labs, and pathology processing. Patients with early-stage LR would undergo endoscopic nasopharyngectomy (ENPG, 70\%) or reirradiation (30\%) [30], while patients with advanced-stage LR would undergo reirradiation. Patients with RR would undergo neck dissection, while patients with DM would receive salvage chemotherapy. The societal costs included costs of transportation, accommodations, meals, and wage loss related to patients' and caregivers' time off work [23, 53-55]. All costs were inflated to 2019 using the medical care component of the Consumer Price Index in China and were converted into 2019 US dollars (exchange rate, $1.00 \mathrm{USD}=6.91 \mathrm{CNY}$ ).

\section{Sensitivity analysis}

One-way sensitivity analyses were applied to parameters over plausible ranges derived from published literature or a deviation of $20 \%$ from the base-case values (Additional file 1: Table S1) [53, 64]. Probabilistic sensitivity analyses (PSA) were conducted using 10,000 Monte Carlo simulations, where all parameters were varied simultaneously based on specific probability distributions (beta distribution for probabilities and utilities; gamma distribution for costs). Cost-effectiveness acceptability curves were constructed based on the strategies' NHB generated from PSA. Additionally, two scenario analyses were performed by varying the surveillance arrangements: every 3 months in years $1-2$ and every 6 months in years 3-5 according to the Radiation Therapy Oncology Group (RTOG) [67, 68]; every 2 months in year 1 , every 4 months in year 2 , and every 6 months in years 3-5 according to the NCCN guidelines for head and neck cancer (Version 1.2021) [19].

\section{Results}

\section{Model validation}

The Markov model-simulated LR-free survival, RR-free survival, and DM-free survival showed good agreement with the real-world disease recurrence patterns (Additional file 1: Fig. S2). In addition, the absolute differences between the model-predicted 1-year, 3-year, and 5-year overall survival and those of the real-world observation were within $2 \%$ in all disease stages, which indicated that the patient's outcomes were comparable between the Markov model and the real-world observation (Additional file 1: Table S4). Collectively, these validation results demonstrated that the Markov model could accurately describe the disease processes of NPC.

\section{Base-case analysis}

The results of the base-case analysis are summarized in Table 1 and Additional file 1: Table S5. With the assistance of cfEBV DNA, cfEBV DNA-guided imaging strategies were considerably more cost-effective than routine imaging strategies across all disease stages. Specifically, compared with cfEBV DNA-guided MRI + CT + BS, the ICERs of routine MRI + CT + BS or routine PET/CT were both exceeding the willingness-to-pay threshold of $\$ 100,000 /$ Q ALY, ranging from \$179,508/QALY in stage IV to $\$ 1,443,575 /$ QALY in stage I (Additional file 1 : Table S5). Similarly, the ICERs of routine imaging strategies compared with cfEBV DNA-guided PET/CT also went far beyond the willingness-to-pay threshold, ranging from $\$ 262,724 /$ QALY in stage IV to $\$ 3,882,176$ / QALY in stage I, and the routine MRI + CT + BS was dominated (less effective but more costly than another strategy) by cfEBV DNA-guided PET/CT in stage IV (Additional file 1: Table S5). Moreover, the NHBs of cfEBV DNA-guided imaging strategies were also greater than those of routine imaging strategies (Table 1). For example, the NHBs of cfEBV DNA-guided MRI + CT + BS and PET/CT were 12.066/QALY and 12.061/QALY in stage II, respectively, larger than those of routine MRI + CT + BS (12.029/QALY) and PET/CT (11.979/QALY).

Next, we scrutinized the most cost-effective strategies in each stage of asymptomatic NPC patients (Table 1). For patients with stage I disease, cfEBV DNA-guided imaging strategies were only associated with a 0.01 gain in QALY compared with routine clinical physical examination. This translated to relatively large ICERs for cfEBV DNA-guided MRI + CT + BS (\$119,368/QALY) and cfEBV DNA-guided PET/CT (\$518,871/QALY), both surpassing the willingness-to-pay threshold. Therefore, routine follow-up was adequate for stage I NPC patients. However, in stage II and III, cfEBV DNA-guided MRI + $\mathrm{CT}+\mathrm{BS}$ was the most cost-effective strategy, with ICERs of $\$ 57,308 /$ QALY and $\$ 46,860 /$ QALY, respectively, compared with routine clinical physical examination. Intriguingly, for patients with stage IV disease, cfEBV DNA-guided PET/CT became the most costeffective, with an ICER of \$62,269/QALY compared with cfEBV DNA-guided MRI + CT + BS. Likewise, the results of NHBs supported the same strategies mentioned above; the strategies with the highest NHBs were routine 
Table 1. Base-case cost-effectiveness analysis

\begin{tabular}{|c|c|c|c|c|c|c|}
\hline \multirow[b]{2}{*}{ Surveillance strategy ${ }^{a}$} & \multicolumn{2}{|c|}{ Total values } & \multicolumn{2}{|c|}{ Incremental values ${ }^{\mathbf{b}}$} & \multirow{2}{*}{$\begin{array}{l}\text { ICER } \\
\text { (\$/QALY) }\end{array}$} & \multirow{2}{*}{$\begin{array}{l}\text { NHB }^{c} \\
(Q A L Y)\end{array}$} \\
\hline & Cost (\$) & $\overline{\text { Effectiveness (QALY) }}$ & Costs (\$) & $\overline{\text { Effectiveness (QALY) }}$ & & \\
\hline \multicolumn{7}{|l|}{ Stage I } \\
\hline Routine clinical physical examination & 5664 & 13.223 & - & - & - & 13.166 \\
\hline cfEBV DNA-guided MRI + CT + BS & 6902 & 13.233 & 1239 & 0.010 & 119,368 & 13.164 \\
\hline cfEBV DNA-guided PET/CT & 8113 & 13.236 & 1210 & 0.002 & 518,871 & 13.155 \\
\hline Routine MRI + CT + BS & 11,546 & 13.237 & 3433 & 0.001 & $3,882,176$ & 13.121 \\
\hline Routine PET/CT & 17,458 & 13.241 & 5913 & 0.004 & 1378,484 & 13.066 \\
\hline \multicolumn{7}{|l|}{ Stage II } \\
\hline Routine clinical physical examination & 6694 & 12.121 & - & - & - & 12.054 \\
\hline cfEBV DNA-guided MRI + CT + BS & 8341 & 12.150 & 1647 & 0.029 & 57,308 & 12.066 \\
\hline cfEBV DNA-guided PET/CT & 9719 & 12.158 & 1378 & 0.009 & 162,041 & 12.061 \\
\hline Routine MRI + CT + BS & 13,098 & 12.160 & 3379 & 0.002 & $1,923,004$ & 12.029 \\
\hline Routine PET/CT & 19,470 & 12.174 & 6373 & 0.014 & 454,793 & 11.979 \\
\hline \multicolumn{7}{|l|}{ Stage III } \\
\hline Routine clinical physical examination & 8421 & 11.452 & - & - & - & 11.367 \\
\hline cfEBV DNA-guided MRI + CT + BS & 10,562 & 11.497 & 2141 & 0.046 & 46,860 & 11.392 \\
\hline cfEBV DNA-guided PET/CT & 12,259 & 11.513 & 1697 & 0.016 & 108,549 & 11.390 \\
\hline Routine MRI + CT + BS & 16,149 & 11.514 & 3891 & 0.001 & $2,780,611$ & 11.353 \\
\hline Routine PET/CT & 23,765 & 11.538 & 7615 & 0.024 & 318,452 & 11.300 \\
\hline \multicolumn{7}{|l|}{ Stage IV } \\
\hline Routine clinical physical examination & 10,101 & 9.869 & - & - & - & 9.768 \\
\hline cfEBV DNA-guided MRI + CT + BS & 12,845 & 9.947 & 2744 & 0.079 & 34,906 & 9.819 \\
\hline cfEBV DNA-guided PET/CT & 14,788 & 9.978 & 1944 & 0.031 & 62,269 & 9.831 \\
\hline Routine MRI + CT + BS & 18,363 & 9.978 & 3574 & -0.001 & Dominated $^{d}$ & 9.794 \\
\hline Routine PET/CT & 26,342 & 10.022 & 11,553 & 0.044 & 262,724 & 9.759 \\
\hline
\end{tabular}

Abbreviations: $B S$, bone scintigraphy; $c f E B V$, cell-free Epstein-Barr virus; $C T$, computed tomography; ICER, incremental cost-effectiveness ratio; $M R I$, magnetic resonance imaging; $N H B$, net health benefit; $P E T / C T$, positron emission tomography/computed tomography; $Q A L Y$, quality-adjusted life-year

${ }^{a}$ Routine clinical physical examination consists of history and physical examinations, complete blood counts, comprehensive metabolic panels and

nasopharyngoscopies. Other strategies also include routine clinical physical examination. Please see the manuscript for the full description of each strategy

${ }^{\mathrm{b}}$ Incremental values were compared with the previous less costly and nondominated strategy

c Calculated at the willingness-to-pay threshold of $\$ 100,000$ using the following formula: effectiveness - cost/willingness-to-pay. Strategies with the highest NHB values, highlighted in bold, are considered the most cost-effective

${ }^{d}$ Refer to a strategy that is less effective and more costly than another strategy

clinical physical examination in stage I (NHB, 13.166/ QALY), cfEBV DNA-guided MRI + CT + BS in stage II (12.066/QALY) and stage III (11.392/QALY), and cfEBV DNA-guided PET/CT in stage IV (9.831/QALY). The preferred strategy in each stage is summarized in Fig. 1.

To further clarify the superiority of cfEBV DNAguided imaging strategies over routine imaging strategies, we compared their average number of imaging studies required to detect one disease recurrence (Table 2). While routine imaging strategies resulted in a 5-year total of 97,493 to 118,328 imaging studies being performed per 10,000 patients, the cfEBV DNA-guided imaging strategies only required 19,676 to 25,893 imaging studies to detect a comparable number of recurrences as routine imaging strategies. Ultimately, compared with routine imaging strategies,
cfEBV DNA-guided imaging strategies only required approximately one quarter of the imaging studies to detect one recurrence. For example, in stage II, routine MRI + CT + BS and routine PET/CT needed 121 and 106 imaging studies to detect one recurrence, respectively, while the guidance of cfEBV DNA decreased the number of imaging studies to 25 and 23, respectively. Therefore, cfEBV DNA-guided imaging strategies were the most favorable option for stage II to IV NPC patients. However, for stage I NPC patients, although the total imaging studies of cfEBV DNA-guided imaging strategies were remarkably fewer than routine imaging strategies, they still required a fair number of studies per recurrence detection (cfEBV DNA-guided MRI + CT + BS, 94; cfEBV DNA-guided PET/CT, 89) due to low recurrence 


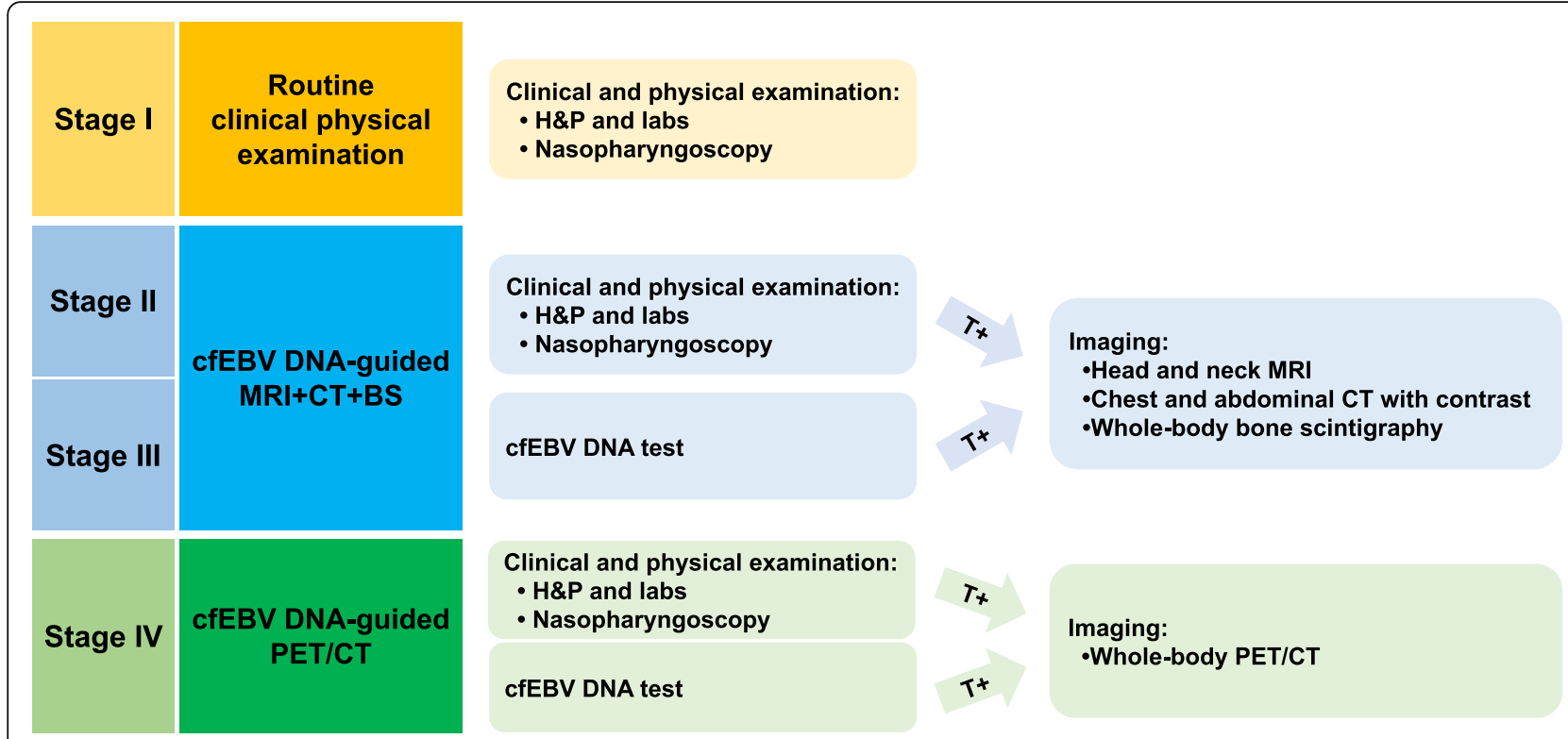

Fig. 1 The cost-effective posttreatment surveillance strategy in each stage of nasopharyngeal carcinoma. The cfEBV DNA-guided MRI + CT + BS and cfEBV DNA-guided PET/CT refer to routine clinical and physical examinations and cfEBV DNA tests, followed by further imaging studies when the results are positive. Abbreviations: BS, bone scintigraphy; cfEBV, cell-free Epstein-Barr virus; CT, computed tomography; H\&P, history and physical examination; MRI, magnetic resonance imaging; PET/CT, positron emission tomography/computed tomography; T, test

probabilities, suggesting that, despite the guidance of cfEBV DNA, imaging was still unfavorable for them. This result was consistent with the cost-effectiveness analysis mentioned above that routine clinical physical examination was enough for patients with stage I disease.

\section{Sensitivity analysis}

To evaluate the results' robustness, sensitivity analyses were performed on all probabilities, utilities, and costs. In one-way sensitivity analyses, cfEBV DNAguided imaging strategies were consistently more cost-effective than routine imaging strategies across the range of all parameters (Additional file 1: Fig. S36). However, the optimal surveillance strategy in each stage was sensitive to several parameters when compared to the next more costly strategies, with key parameters displayed in Fig. 2A-D.

In stage I, the optimal strategy was sensitive to the LR probabilities and the specificity of routine clinical physical examination for RR (Fig. 2A). When increasing the LR probabilities to $2.1 \%$ or decreasing the specificity of routine clinical physical examination for RR to $65.9 \%$, the preferred strategy would switch from routine clinical physical examination to cfEBV DNA-guided MRI + CT + BS. Nevertheless, all ICERs remained higher than $\$ 87,000 / Q A L Y$ when varying the parameters. In stage II-IV, the cost of PET/CT was the principal determinant of the ICERs (Fig. 2B-D). Specifically, if the PET/CT's cost was reduced to $\$ 1221$, the cfEBV DNA-guided
PET/CT would become the optimal strategy in stage III. Conversely, although the cost of PET/CT also had the greatest impact on the ICERs in stage II and IV, varying it did not change the optimal surveillance strategies in the base-case analysis.

The PSA results are illustrated in the costeffectiveness acceptability curves shown in Fig. 3A-D. With the willingness-to-pay threshold varying from 0 to $\$ 200,000 /$ QALY, the probabilities of routine imaging strategies being the optimal strategies were almost zero in stage I-III and less than $10.0 \%$ in stage IV. At a willingness-to-pay threshold of $\$ 100,000 /$ QALY, routine clinical physical examination was the most cost-effective in $78.2 \%$ of the simulations for stage I patients; cfEBV DNA-guided MRI + CT + BS was the most cost-effective in $88.4 \%$ and $56.3 \%$ of the simulations for stage II and III patients, respectively; and cfEBV DNA-guided PET/CT was the most costeffective in $96.2 \%$ of the simulations for stage IV patients.

To examine the cost-effectiveness of cfEBV DNAguided strategies under different follow-up arrangements, we performed two scenario analyses using the recommended arrangements from the RTOG and NCCN guidelines (Additional file 1: Table S6) [19, 67, 68]. For both scenarios, cfEBV DNA-guided imaging strategies were consistently more cost-effective than routine imaging strategies. The optimal surveillance strategy in each disease stage was in line with the base-case results. 
Table 2 Number of disease recurrences detected by imaging studies in 5 years per 10,000 patients

\begin{tabular}{|c|c|c|c|c|c|c|}
\hline Surveillance strategy & $\begin{array}{l}\text { Imaging-detected } \\
\text { local relapse }\end{array}$ & $\begin{array}{l}\text { Imaging-detected } \\
\text { regional relapse }\end{array}$ & $\begin{array}{l}\text { Imaging-detected } \\
\text { distant metastasis }\end{array}$ & $\begin{array}{l}\text { Total imaging } \\
\text { studies performed }\end{array}$ & $\begin{array}{l}\text { Imaging studies } \\
\text { per recurrence }\end{array}$ & $P^{\mathbf{b}}$ \\
\hline \multicolumn{7}{|l|}{ Stage I } \\
\hline $\begin{array}{l}\text { CfEBV DNA-guided } \\
M R I+C T+B S\end{array}$ & 102 & 20 & 87 & 19,703 & 94 & \\
\hline $\begin{array}{l}\text { CfEBV DNA-guided } \\
\mathrm{PET} / \mathrm{CT}\end{array}$ & 103 & 21 & 98 & 19,676 & 89 & \\
\hline Routine MRI + CT + BS & 112 & 23 & 78 & 97,493 & 457 & $<.001$ \\
\hline Routine PET/CT & 119 & 24 & 99 & 97,519 & 405 & $<.001$ \\
\hline \multicolumn{7}{|l|}{ Stage II } \\
\hline $\begin{array}{l}\text { CfEBV DNA-guided } \\
M R I+C T+B S\end{array}$ & 199 & 306 & 354 & 21,265 & 25 & \\
\hline $\begin{array}{l}\text { CfEBV DNA-guided } \\
\mathrm{PET} / \mathrm{CT}\end{array}$ & 202 & 307 & 399 & 21,170 & 23 & \\
\hline Routine MRI + CT + BS & 216 & 316 & 309 & 101,670 & 121 & $<.001$ \\
\hline Routine PET/CT & 228 & 319 & 410 & 101,595 & 106 & $<.001$ \\
\hline \multicolumn{7}{|l|}{ Stage III } \\
\hline $\begin{array}{l}\text { cfEBV DNA-guided } \\
M R I+C T+B S\end{array}$ & 344 & 339 & 596 & 25,010 & 20 & \\
\hline $\begin{array}{l}\text { CfEBV DNA-guided } \\
\mathrm{PET} / \mathrm{CT}\end{array}$ & 349 & 340 & 671 & 24,855 & 18 & \\
\hline Routine MRI + CT + BS & 368 & 349 & 538 & 118,328 & 94 & $<.001$ \\
\hline Routine PET/CT & 389 & 350 & 672 & 118,204 & 84 & $<.001$ \\
\hline \multicolumn{7}{|l|}{ Stage IV } \\
\hline $\begin{array}{l}\text { cfEBV DNA-guided } \\
\text { MRI }+C T+B S\end{array}$ & 571 & 484 & 1166 & 25,893 & 12 & \\
\hline $\begin{array}{l}\text { cfEBV DNA-guided } \\
\text { PET/CT }\end{array}$ & 580 & 486 & 1324 & 25,598 & 11 & \\
\hline Routine MRI + CT + BS & 610 & 502 & 1101 & 117,829 & 53 & $<.001$ \\
\hline Routine PET/CT & 640 & 508 & 1372 & 117,440 & 47 & $<.001$ \\
\hline
\end{tabular}

Abbreviations: $B S$, bone scintigraphy; $C F E B V$, cell-free Epstein-Barr virus; $C T$, computed tomography; $M R I$, magnetic resonance imaging; $P E T / C T$, positron emission tomography/computed tomography

${ }^{a}$ Indicate the number of imaging studies required to detect one recurrence, which was calculated by dividing the number of total imaging studies by the number of imaging-detected disease recurrences (including local relapse, regional relapse and distant metastasis).

${ }^{\mathrm{b}}$ Two-sided $P$ values were calculated using Welch's $t$-test for comparisons between cfEBV DNA-guided MRI + CT + BS and routine MRI + CT + BS; cfEBV DNA-

guided PET/CT and routine PET/CT

\section{Discussion}

To our knowledge, this is the first study to evaluate the liquid biopsy-based surveillance in NPC patients. We found that the cfEBV DNA-guided imaging strategies were remarkably more cost-effective than routine imaging strategies. Specifically, cfEBV DNA-guided MRI + CT + BS was cost-effective for stage II and III patients, while cfEBV DNA-guided PET/CT was cost-effective for stage IV patients. However, routine follow-up was sufficient for stage I NPC patients due to their low recurrence probabilities. Overall, our results highlight the feasibility of cfEBV DNA in the surveillance of NPC.

According to the current NCCN guideline, routine surveillance imaging was not recommended in asymptomatic patients [19], and our analysis agreed with it. However, directly halting imaging would result in delayed diagnoses of recurrence, especially for distant recurrence because many patients are asymptomatic $[19,69]$. In fact, surveillance imaging was the most widely used follow-up modality in NPC, and $79 \%$ of clinicians would order routine imaging in clinical practice for reassurance, patient requests, etc. [70]. Consequently, undifferentiated imaging surveillance has resulted in considerable economic burdens and resource consumption. Given these circumstances, it is urgent to establish a convenient and reliable method that can distinguish patients at high risk of developing recurrence so as to focus imaging surveillance on them.

cfEBV DNA is an ideal biomarker with low expense and high sensitivity in suggesting disease recurrence. The ESMO and NCCN guidelines both recommended 


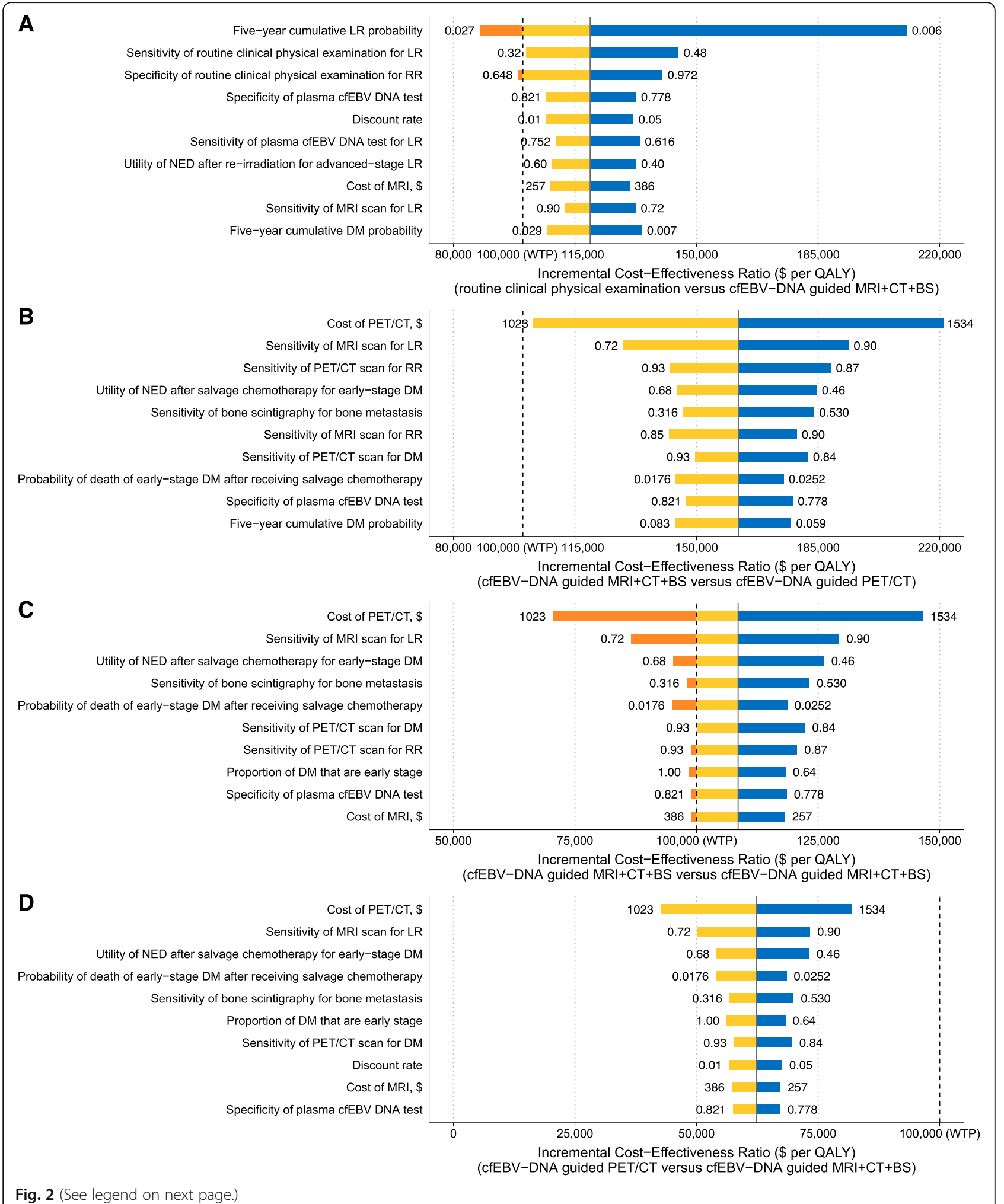


(See figure on previous page.)

Fig. 2 Tornado diagram of one-way sensitivity analysis. The figure depicts the influence of the variation of each parameter on the ICERs between A routine clinical physical examination and cfEBV DNA-guided MRI $+C T+B S$ in patients with stage I NPC; cfEBV DNA-guided MRI + CT + BS and cfEBV DNA-guided PET/CT in patients with stage $\mathbf{B}$ II, C III, and $\mathbf{D}$ IV NPC. The parameters accounting for the top 10 uncertainties in each comparison are displayed. The blue bars and red bars illustrate the ICERs that are greater and less than the base-case ICERs, respectively. The orange bars indicate that the ICERs go across the willingness-to-pay threshold, leading to a switch of the most cost-effective strategy. The numbers on both sides of the bars indicate the range of each parameter used in the sensitivity analysis. The solid and dashed lines represent the ICERs in the base-case analysis and the willingness-to-pay threshold of $\$ 100,000$ per quality-adjusted life-year, respectively. Abbreviations: BS, bone scintigraphy; cfEBV, cell-free Epstein-Barr virus; CT, computed tomography; DM, distant metastasis; ICER, incremental cost-effectiveness ratio; LR, local relapse; MRI, magnetic resonance imaging; NPC, nasopharyngeal carcinoma; PET/CT, positron emission tomography/computed tomography; $\mathrm{RR}$, regional relapse; WTP, willingness-to-pay

cfEBV DNA tests in NPC follow-up [17, 19]. Therefore, cfEBV DNA-guided imaging strategies are particularly promising. Using cfEBV DNA, patients at risk of recurrence can be identified in order to concentrate surveillance imaging on those who will benefit, thus sparing the unnecessary expense and radiation exposure for those who will not. Compared with routine imaging surveillance, targeting imaging to patients with positive cfEBV DNA gained similar survival benefits but only required one quarter of the imaging to detect one recurrence. This liquid biopsy-based surveillance strategy underscores the practice of precision medicine in the follow-up of cancer survivors, which has been investigated in several malignancies [71-73]. For example, Roschewski et al. [72] found that surveillance circulating tumor DNA could accurately suggest recurrence in diffuse large B cell lymphoma, leading to reduced disease burden at recurrence.

Until now, few studies have investigated the optimal follow-up modalities for each stage of NPC [30]. Consequently, despite the substantial heterogeneity of recurrence risk in different disease stages of NPC [1,22], the
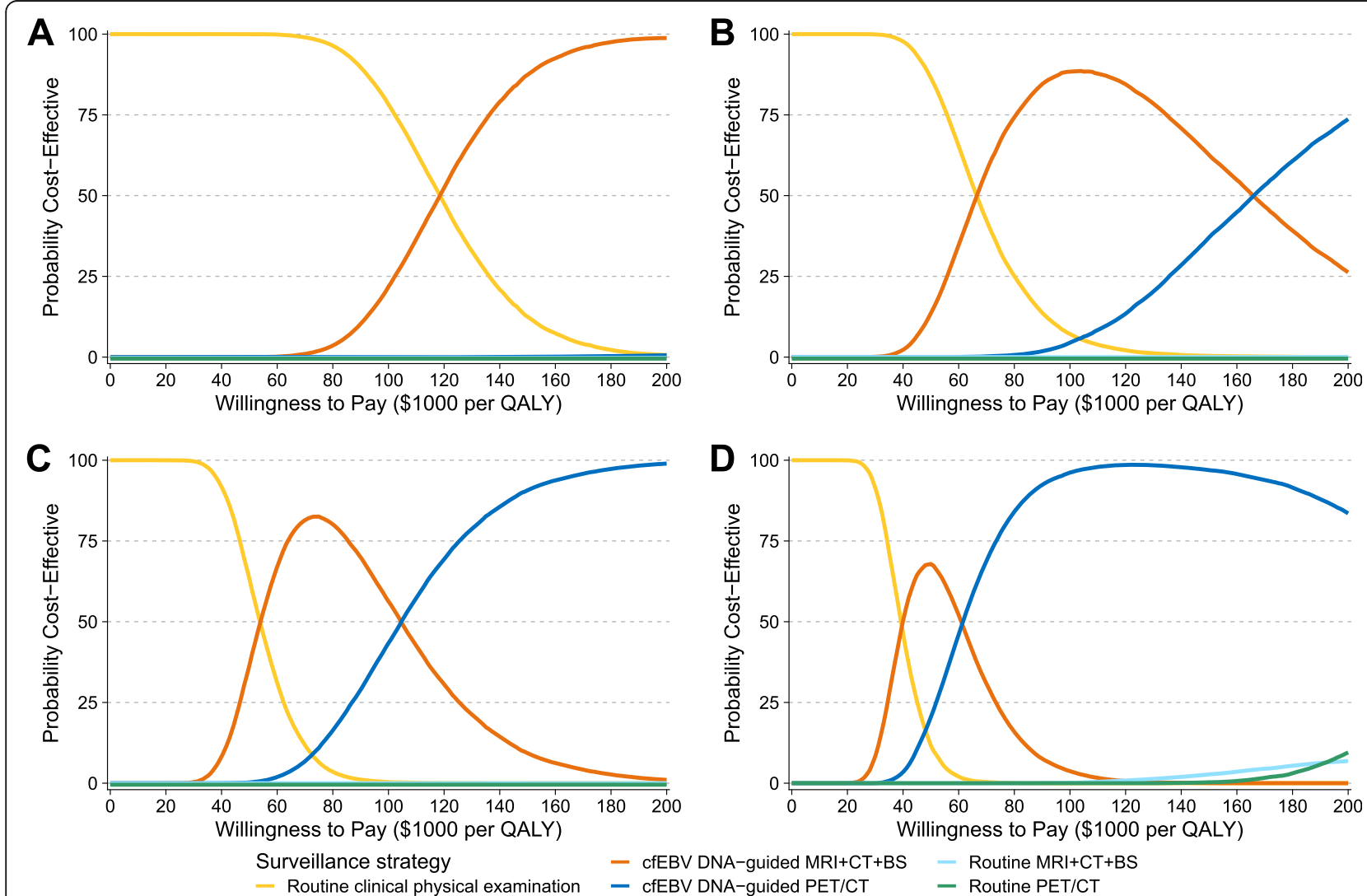

Fig. 3 Cost-effectiveness acceptability curves. The figure illustrates the acceptability of each surveillance strategy in the probabilistic sensitivity analysis for stage I (A), II (B), III (C), and IV (D) NPC patients. The curves in different colors illustrate the probability of each surveillance strategy being the most cost-effective at a given willingness-to-pay threshold. Abbreviations: BS, bone scintigraphy; cfEBV, cell-free Epstein-Barr virus; CT, computed tomography; MRI, magnetic resonance imaging; NPC, nasopharyngeal carcinoma; PET/CT, positron emission tomography/computed tomography; QALY, quality-adjusted life-year 
ESMO and NCCN guideline failed to recommend stagespecific follow-up strategies [17, 19]. Zhou et al. [30] evaluated the cost-effectiveness of surveillance MRI and recommended annual MRI for patients with advanced tumor stage and no MRI for early stage. However, they did not consider distant recurrence, the predominant failure pattern in NPC [1]. Besides, they did not investigate cfEBV DNA and PET/CT, which have been widely adopted in clinical practice. Our study addressed these unmet needs. We found that cfEBV DNA-guided imaging surveillance is particularly preferable for stage IIIV NPC patients, where selected MRI + CT + BS or PET/CT were performed depending on their disease stages. However, for stage I patients, cfEBV DNA-guided imaging is not recommended due to their fairly good survival, with 10-year overall survival and recurrencefree survival both greater than 95\% [74]. Hence, routine follow-up would be sufficient for stage I NPC patients.

Evidence has indicated that PET/CT was more effective than other imaging modalities in detecting recurrent NPC, especially for distant recurrence $[19,31,34,37$, 75]. However, lacking guidance regarding when to perform PET/CT during NPC surveillance, clinicians have to be critically cautious about prescribing costly PET/CT when following up patients with relatively poor economic conditions. In this study, we found that cfEBV DNA could be a precise indicator to perform PET/CT for patients at risk of recurrence, which was costeffective in stage IV NPC patients. In addition, we observed that the cost of PET/CT predominantly determined the ICERs between cfEBV DNA-guided PET/CT and cfEBV DNA-guided MRI + CT + BS in the sensitivity analyses. With the discounting of PET/CT, cfEBV DNA-guide PET/CT will be increasingly cost-effective. Therefore, the tradeoffs between the two strategies should be continuously recalibrated to reflect the updated cost of PET/CT in clinical practice, especially among stage III NPC patients where cfEBV DNA-guided $\mathrm{PET} / \mathrm{CT}$ was near the most cost-effective strategy.

With the growing recognition that cfEBV DNA possessed favorable performance in detecting tumor recurrence [13-16, 76], we proposed cfEBV DNA-guided surveillance strategies as references for patients and clinicians in NPC follow-up. Nevertheless, our recommendations should be implemented cautiously. First, although cfEBV DNA demonstrates high sensitivity in detecting $R R$ and $D M$, it is relatively insensitive to $L R$ $[13,14,16,76]$. Therefore, cfEBV DNA results should be interpreted with the history and physical examinations and nasopharyngoscopies to comprehensively evaluate the local conditions [76]. Second, cfEBV DNA levels might elevate even before recurrences can be detected on imaging $[16,76]$. Hence, patients with detectable cfEBV DNA but negative imaging might require subsequent cfEBV DNA tests (e.g., another cfEBV DNA test 1-3 months later) to distinguish much earlier-stage recurrence from false-positive results, especially for those with high recurrence risk [16].

Several limitations need to be noted. First, the inherent shortcoming of the decision-analytic model was the model inputs determined from various sources. We therefore conducted extensive sensitivity analyses to clarify the uncertainty, and the cfEBV DNA-guided imaging strategy was confirmed to be robustly costeffective in the sensitivity analysis. Second, the model did not account for secondary recurrences because our study population was patients achieving $\mathrm{CR}$ to the primary treatment for NPC. Patients who have experienced recurrence will manifest distinct risks of disease failure, and thus may require different surveillance strategies $[8$, 77]. Third, since the study is from the Chinese societal perspective, the results might vary with different medical and societal costs. Accordingly, similar analyses in other regions are warranted. Last but not least, the study does not account for non-endemic NPC. NPC in endemic areas, including southern China, Southeast Asia, and North and East Africa, constitutes more than $80 \%$ of new cases worldwide [78-80], which are mostly the non-keratinising subtype ( $>95 \%$ ) and are invariably associated with EBV infection [81]. However, the keratinising squamous subtype is more common in regions where NPC is non-endemic, e.g., North America and northern Europe [81, 82]. Evidence has indicated that patients with the keratinising squamous subtype tend to have worse survival, poorer local control, and less distant failures than those with the non-keratinising subtype; and their association with EBV infection is relatively low [81-84]. Therefore, the applicability of cfEBV DNAguided surveillance strategies should be carefully reevaluated in non-endemic areas.

\section{Conclusions}

In this model-based analysis of follow-up strategies in NPC, we proposed cfEBV DNA-guided imaging strategies that were the most cost-effective for stage II-IV patients. The liquid biopsy-based surveillance strategies are of high clinical feasibility, which simultaneously takes patient outcomes and resource consumption into account. In the precision medicine era, these results would add new insight into the momentum of liquid biopsy in the surveillance of cancer survivors.

\section{Abbreviations}

BS: Bone scintigraphy; cfEBV: Circulating cell-free Epstein-Barr virus; ESMO: European Society for Medical Oncology; ICER: Incremental costeffectiveness ratio; NPC: Nasopharyngeal carcinoma; NCCN: National

Comprehensive Cancer Network; NHB: Net health benefit; PET/CT: Positron emission tomography/computed tomography; PSA: Probabilistic sensitivity analyses; QALY: Quality-adjusted life-year 


\section{Supplementary Information}

The online version contains supplementary material available at https://doi. org/10.1186/s12916-021-02076-4.

\section{Additional file 1: Table S1. Model parameters. Table S2.}

Characteristics of 10,097 patients with nonmetastatic nasopharyngeal carcinoma. Table S3. Age-specific background mortality rate. Table S4. Model validation of the Markov model-predicted overall survival compared with the real-world observed overall survival. Table S5. Base-case cost-effectiveness analysis comparing cfEBV DNA-guided imaging strategies with routine imaging strategies. Table S6. Cost-effectiveness scenario analyses using the RTOG and NCCN surveillance arrangements. Fig. S1. Schematic diagram of the surveillance strategies and the structure of the Markov model. Fig. S2. Validation of the Markov model. Fig. S3. Tornado diagram of one-way sensitivity analysis for stage I NPC patients.

Fig. S4. Tornado diagram of one-way sensitivity analysis for stage II NPC patients. Fig. S5. Tornado diagram of one-way sensitivity analysis for stage III NPC patients. Fig. S6. Tornado diagram of one-way sensitivity analysis for stage IV NPC patients.

Additional file 2. Supplementary methods.

\section{Acknowledgements}

Not applicable.

\section{Authors' contributions}

YS, GQZ, CFW, LL, YPM, and BD participated in the study concept and design. YS, GQZ, and JM provided administrative support. GQZ, CFW, and LL performed the data acquisition. CFW, LL, YPM, BD, JWL, WHZ, DWW, JK, FPC, XLY, SSX, and GQZ performed the data analysis and interpretation. All authors contributed to the manuscript writing, critical revision, and final approval of the manuscript.

\section{Funding}

This work was supported by the Key-Area Research and Development Program of Guangdong Province (2020B1111190001, 2019B020230002) and the Natural Science Foundation of Guangdong Province (2017A030312003). The funders played no role in the design of the study, collection, analysis, and interpretation of data or in writing the manuscript.

\section{Availability of data and materials}

The patient-level data utilized in the study, including patient characteristics, treatments, and survival outcomes, have been deposited in the Research Data Deposit public platform with the accession RDD number: RDDA2021001822 (https://www.researchdata.org.cn/Search.aspx?Num = RDDA2021001822); and the data are available from the corresponding authors on reasonable request. All the other data of the study are available within the article and the additional files and from the corresponding authors upon reasonable request.

\section{Declarations}

\section{Ethics approval and consent to participate}

The study protocol was approved by the institutional ethics committee of Sun Yat-sen University Cancer Center (B2020-410). Given the retrospective nature of the study, the requirement for informed consent was waived.

\section{Consent for publication}

Not applicable.

\section{Competing interests}

The authors declare that they have no competing interests.

\section{Author details}

'Department of Radiation Oncology, Sun Yat-sen University Cancer Center; State Key Laboratory of Oncology in South China, Collaborative Innovation Center for Cancer Medicine, Guangdong Key Laboratory of Nasopharyngeal Carcinoma Diagnosis and Therapy, 651 Dongfeng Road East, Guangzhou 510060, Guangdong, People's Republic of China. ²Department of Radiation Oncology, Wuzhou Red Cross Hospital, Wuzhou 543002, Guangxi, People's Republic of China.
Received: 25 May 2021 Accepted: 27 July 2021

Published online: 26 August 2021

\section{References}

1. Mao YP, Tang LL, Chen L, Sun Y, Qi ZY, Zhou GQ, et al. Prognostic factors and failure patterns in non-metastatic nasopharyngeal carcinoma after intensity-modulated radiotherapy. Chin J Cancer. 2016;35(1):103. https://doi. org/10.1186/s40880-016-0167-2.

2. Zhang MX, Li J, Shen GP, Zou X, Xu JJ, Jiang R, et al. Intensity-modulated radiotherapy prolongs the survival of patients with nasopharyngeal carcinoma compared with conventional two-dimensional radiotherapy: A 10-year experience with a large cohort and long follow-up. Eur J Cancer. 2015;51(17):2587-95. https://doi.org/10.1016/j.ejca.2015.08.006.

3. Zheng WH, He XJ, Chen FP, Lin L, Huang XD, Zhou HQ, et al. Establishing M1 stage subdivisions by incorporating radiological features and EpsteinBarr virus DNA for metastatic nasopharyngeal carcinoma. Ann Transl Med. 2020;8(4):83. https://doi.org/10.21037/atm.2020.01.13.

4. Hua YJ, Han F, Lu LX, Mai HQ, Guo X, Hong MH, et al. Long-term treatment outcome of recurrent nasopharyngeal carcinoma treated with salvage intensity modulated radiotherapy. Eur J Cancer. 2012;48(18):3422-8. https:// doi.org/10.1016/j.ejca.2012.06.016.

5. Li YQ, Tian YM, Tan SH, Liu MZ, Kusumawidjaja G, Ong EHW, et al. Prognostic model for stratification of radioresistant nasopharynx carcinoma to curative salvage radiotherapy. J Clin Oncol. 2018;36(9):891-9. https://doi. org/10.1200/JCO.2017.75.5165.

6. Hu J, Bao C, Gao J, Guan X, Hu W, Yang J, et al. Salvage treatment using carbon ion radiation in patients with locoregionally recurrent nasopharyngeal carcinoma: Initial results. Cancer. 2018;124(11):2427-37. https://doi.org/10.1002/cncr.31318.

7. Roman BR, Goldenberg D, Givi B. AHNS Series--Do you know your guidelines? Guideline recommended follow-up and surveillance of head and neck cancer survivors. Head Neck. 2016;38(2):168-74. https://doi.org/1 $0.1002 /$ hed 24100

8. Chen YP, Chan ATC, Le QT, Blanchard P, Sun Y, Ma J. Nasopharyngeal carcinoma. Lancet. 2019;394(10192):64-80. https://doi.org/10.1016/S01406736(19)30956-0.

9. Chan KCA, Woo JKS, King A, Zee BCY, Lam WKJ, Chan SL, et al. Analysis of plasma Epstein-Barr virus DNA to screen for nasopharyngeal cancer. N Engl J Med. 2017;377(6):513-22. https://doi.org/10.1056/NEJMoa1701717.

10. Guo R, Tang LL, Mao YP, Du XJ, Chen L, Zhang ZC, et al. Proposed modifications and incorporation of plasma Epstein-Barr virus DNA improve the TNM staging system for Epstein-Barr virus-related nasopharyngeal carcinoma. Cancer. 2019;125(1):79-89. https://doi.org/10.1002/cncr.31741.

11. Lv J, Chen Y, Zhou G, Qi Z, Tan KRL, Wang H, et al. Liquid biopsy tracking during sequential chemo-radiotherapy identifies distinct prognostic phenotypes in nasopharyngeal carcinoma. Nat Commun. 2019;10(1):3941. https://doi.org/10.1038/s41467-019-11853-y.

12. Chan ATC, Hui EP, Ngan RKC, Tung SY, Cheng ACK, Ng WT, Lee VHF, Ma BBY, Cheng HC, Wong FCS, et al. Analysis of plasma Epstein-Barr virus DNA in nasopharyngeal cancer after chemoradiation to identify high-risk patients for adjuvant chemotherapy: a randomized controlled trial. J Clin Oncol 2018:Jco2018777847.

13. Hsu CL, Chan SC, Chang KP, Lin TL, Lin CY, Hsieh CH, et al. Clinical scenario of EBV DNA follow-up in patients of treated localized nasopharyngeal carcinoma. Oral Oncol. 2013;49(6):620-5. https://doi.org/10.1016/j.ora loncology.2013.02.006.

14. Wang WY, Twu CW, Lin WY, Jiang RS, Liang KL, Chen KW, et al. Plasma Epstein-Barr virus DNA screening followed by ${ }^{18}$ F-fluoro-2-deoxy-D-glucose positron emission tomography in detecting posttreatment failures of nasopharyngeal carcinoma. Cancer. 2011;117(19):4452-9. https://doi.org/10.1 $002 /$ cncr.26069.

15. Li WF, Zhang Y, Huang XB, Du XJ, Tang LL, Chen L, et al. Prognostic value of plasma Epstein-Barr virus DNA level during posttreatment follow-up in the patients with nasopharyngeal carcinoma having undergone intensitymodulated radiotherapy. Chin J Cancer. 2017;36(1):87. https://doi.org/10.11 86/s40880-017-0256-X

16. Chen FP, Huang XD, Lv JW, Wen DW, Zhou GQ, Lin L, et al. Prognostic potential of liquid biopsy tracking in the posttreatment surveillance of patients with nonmetastatic nasopharyngeal carcinoma. Cancer. 2020; 126(10):2163-73. https://doi.org/10.1002/cncr.32770. 
17. Bossi P, Chan AT, Licitra L, Trama A, Orlandi E, Hui EP, et al. Nasopharyngeal carcinoma: ESMO-EURACAN Clinical Practice Guidelines for diagnosis, treatment and follow-up. Ann Oncol. 2020.

18. Lo YM, Chan LY, Chan AT, Leung SF, Lo KW, Zhang J, et al. Quantitative and temporal correlation between circulating cell-free Epstein-Barr virus DNA and tumor recurrence in nasopharyngeal carcinoma. Cancer Res. 1999; 59(21):5452-5

19. Pfister DG, Spencer S, Adelstein D, Adkins D, Brizel DM, Bruce JY, Busse PM, Caudell JJ, Cmelak AJ. NCCN Clinical Practice Guidelines in Oncology: Head and Neck Cancers. Version 1.2021. https://www.nccn.org. Accessed 12 Nov, 2020.

20. Zhou G-Q, Wu C-F, Deng B, Gao T-S, Lv J-W, Lin L, Chen F-p, Kou J, Zhang Z-X, Huang X-D, et al. An optimal posttreatment surveillance strategy for cancer survivors based on an individualized risk-based approach. Nature Communications 2020, 11(1):3872.

21. Lee AW, Foo W, Law SC, Poon YF, Sze WM. O SK, Tung SY, Chappell R, Lau $\mathrm{WH}, \mathrm{Ho} \mathrm{JH}$. Recurrent nasopharyngeal carcinoma: the puzzles of long latency. International journal of radiation oncology, biology, physics. 1999; 44(1):149-56. https://doi.org/10.1016/S0360-3016(98)00524-0.

22. Liu X, Tang LL, Du XJ, Li WF, Chen L, Zhou GQ, et al. Changes in disease failure risk of nasopharyngeal carcinoma over time: analysis of 749 patients with long-term follow-up. J Cancer. 2017;8(3):455-9. https://doi.org/10.7150/ jca.17104.

23. Sanders GD, Neumann PJ, Basu A, Brock DW, Feeny D, Krahn M, et al. Recommendations for conduct, methodological practices, and reporting of cost-effectiveness analyses: second panel on cost-effectiveness in health and medicine. Jama. 2016;316(10):1093-103. https://doi.org/10.1001/jama.2 016.12195 .

24. Braithwaite RS, Meltzer DO, King JT Jr, Leslie D, Roberts MS. What does the value of modern medicine say about the $\$ 50,000$ per quality-adjusted lifeyear decision rule? Med Care. 2008;46(4):349-56. https://doi.org/10.1097/ MLR.0b013e31815c31a7.

25. Neumann PJ, Cohen JT, Weinstein MC. Updating cost-effectiveness--the curious resilience of the $\$ 50,000-$ per-QALY threshold. N Engl J Med. 2014; 371(9):796-7. https://doi.org/10.1056/NEJMp1405158.

26. Stinnett AA, Mullahy J. Net health benefits: a new framework for the analysis of uncertainty in cost-effectiveness analysis. Med Decis Making. 1998;18(2 Suppl):S68-80. https://doi.org/10.1177/0272989X98018002S09.

27. Husereau D, Drummond M, Petrou S, Carswell C, Moher D, Greenberg D, et al. Consolidated Health Economic Evaluation Reporting Standards (CHEERS)--explanation and elaboration: a report of the ISPOR Health Economic Evaluation Publication Guidelines Good Reporting Practices Task Force. Value Health. 2013;16(2):231-50. https://doi.org/10.1016/j.jval.2013.02. 002.

28. Kwong DL, Nicholls J, Wei WI, Chua DT, Sham JS, Yuen PW, et al. Correlation of endoscopic and histologic findings before and after treatment for nasopharyngeal carcinoma. Head Neck. 2001;23(1):34-41. https://doi.org/1 0.1002/1097-0347(200101)23:1<34:.AID-HED6>3.0.CO;2-\#.

29. Ragab SM, Erfan FA, Khalifa MA, Korayem EM, Tawfik HA. Detection of local failures after management of nasopharyngeal carcinoma: a prospective, controlled trial. J Laryngol Otol. 2008;122(11):1230-4. https://doi.org/10.101 7/S0022215108002016.

30. Zhou GQ, Wu CF, Zhang J, Mao YP, Tang LL, Chen L, et al. Costeffectiveness analysis of routine magnetic resonance imaging in the followup of patients with nasopharyngeal carcinoma after intensity modulated radiation therapy. Int J Radiat Oncol Biol Phys. 2018;102(4):1382-91. https:// doi.org/10.1016/j.jijrobp.2018.01.117

31. Li Z, Li Y, Li N, Shen L. Positron emission tomography/computed tomography outperforms MRI in the diagnosis of local recurrence and residue of nasopharyngeal carcinoma: An update evidence from 44 studies. Cancer Med. 2019;8(1):67-79. https://doi.org/10.1002/cam4.1882.

32. Merritt RM, Williams MF, James TH, Porubsky ES. Detection of cervical metastasis. A meta-analysis comparing computed tomography with physical examination. Arch Otolaryngol Head Neck Surg. 1997;123(2):149-52. https:// doi.org/10.1001/archotol.1997.01900020027004.

33. Chen WS, Li JJ, Hong L, Xing ZB, Wang F, Li CQ. Comparison of MRI, CT and 18F-FDG PET/CT in the diagnosis of local and metastatic of nasopharyngeal carcinomas: an updated meta analysis of clinical studies. Am J Transl Res. 2016;8(11):4532-47.

34. Shen G, Zhang W, Jia Z, Li J, Wang Q, Deng H. Meta-analysis of diagnostic value of 18F-FDG PET or PET/CT for detecting lymph node and distant metastases in patients with nasopharyngeal carcinoma. Br J Radiol. 2014; 87(1044):20140296. https://doi.org/10.1259/bjr.20140296.

35. Gao G, Gong B, Shen W. Meta-analysis of the additional value of integrated 18FDG PET-CT for tumor distant metastasis staging: comparison with 18FDG PET alone and CT alone. Surg Oncol. 2013;22(3):195-200. https://doi.org/10.1 016/j.suronc.2013.06.004.

36. Xu C, Zhang R, Zhang H, Zhang Z. Comparison of (18)FDG PET/PET-CT and bone scintigraphy for detecting bone metastases in patients with nasopharyngeal cancer: a meta-analysis. Oncotarget. 2017;8(35):59740-7. https://doi.org/10.18632/oncotarget.20026.

37. Xu C, Zhang Y, Peng L, Liu X, Li WF, Sun Y, et al. Optimal modality for detecting distant metastasis in primary nasopharyngeal carcinoma during initial staging: a systemic review and meta-analysis of 1774 patients. J Cancer. 2017;8(7):1238-48. https://doi.org/10.7150/jca.18361.

38. Lv JW, Chen YP, Huang XD, Zhou GQ, Chen L, Li WF, et al. Hepatitis B virus screening and reactivation and management of patients with nasopharyngeal carcinoma: a large-scale, big-data intelligence platformbased analysis from an endemic area. Cancer. 2017;123(18):3540-9. https:// doi.org/10.1002/cncr.30775.

39. Yang J, Song X, Sun X, Liu Q, Hu L, Yu H, et al. Outcomes of recurrent nasopharyngeal carcinoma patients treated with endoscopic nasopharyngectomy: a meta-analysis. Int Forum Allergy Rhinol. 2020;10(8): 1001-11. https://doi.org/10.1002/alr.22552.

40. Han F, Zhao C, Huang SM, Lu LX, Huang Y, Deng XW, et al. Long-term outcomes and prognostic factors of re-irradiation for locally recurrent nasopharyngeal carcinoma using intensity-modulated radiotherapy. Clin Oncol (R Coll Radiol). 2012;24(8):569-76. https://doi.org/10.1016/j.clon.2 011.11.010.

41. Tian YM, Tian YH, Zeng L, Liu S, Guan Y, Lu TX, et al. Prognostic model for survival of local recurrent nasopharyngeal carcinoma with intensitymodulated radiotherapy. Br J Cancer. 2014;110(2):297-303. https://doi.org/1 $0.1038 /$ bjc.2013.715

42. Tian YM, Huang WZ, Yuan X, Bai L, Zhao C, Han F. The challenge in treating locally recurrent T3-4 nasopharyngeal carcinoma: the survival benefit and severe late toxicities of re-irradiation with intensity-modulated radiotherapy. Oncotarget. 2017;8(26):43450-7. https://doi.org/10.18632/oncotarget.15896.

43. Lo WC, Wang CP, Ko JY, Lou PJ, Yang TL, Wang CW, et al. Salvage treatment for isolated regional failure of nasopharyngeal carcinoma after primary radiotherapy. Ann Surg Oncol. 2012;19(3):1001-8. https://doi.org/10.1245/s1 0434-011-2018-3.

44. Li X, Lin C, Yan J, Chen Q, Sun X, Liu S, et al. Establishment of a prognostic scoring model for regional recurrent nasopharyngeal carcinoma after neck dissection. Cancer Biol Med. 2020;17(1):227-36. https://doi.org/10.20892/j. issn.2095-3941.2019.0263.

45. Shen L, Li W, Wang S, Xie G, Zeng Q, Chen C, et al. Image-based multilevel subdivision of M1 category in TNM staging system for metastatic nasopharyngeal carcinoma. Radiology. 2016;280(3):805-14. https://doi.org/1 0.1148 /radiol.2016151344.

46. World Health Organization. Life tables by country, China. 2018. https://apps. who.int/gho/data/view.main.60340. Accessed Jun 6, 2020.

47. Wu Q, Liao W, Huang J, Zhang P, Zhang N, Li Q. Cost-effectiveness analysis of gemcitabine plus cisplatin versus docetaxel, cisplatin and fluorouracil for induction chemotherapy of locoregionally advanced nasopharyngeal carcinoma. Oral Oncol. 2020;103:104588. https://doi.org/10.1016/j.ora loncology.2020.104588.

48. Yen RF, Yen MF, Hong RL, Tzen KY, Chien CR, Chen TH. The cost-utility analysis of 18-fluoro-2-deoxyglucose positron emission tomography in the diagnosis of recurrent nasopharyngeal carcinoma. Acad Radiol. 2009;16(1): 54-60. https://doi.org/10.1016/j.acra.2008.06.012.

49. de Almeida JR, Villanueva NL, Moskowitz AJ, Miles BA, Teng MS, Sikora A, et al. Preferences and utilities for health states after treatment for oropharyngeal cancer: transoral robotic surgery versus definitive (chemo)radiotherapy. Head Neck. 2014;36(7):923-33. https://doi.org/10.1002/ hed. 23340.

50. Meregaglia M, Cairns J. A systematic literature review of health state utility values in head and neck cancer. Health Qual Life Outcomes. 2017;15(1):174. https://doi.org/10.1186/s12955-017-0748-z.

51. Szabo SM, Dobson RL, Donato BMK, L'Italien G, Hotte SJ, Levy AR. The quality-of-life impact of head and neck cancer: preference values from the canadian general public. Health Outcomes Research in Medicine. 2012;3(1): e11-23. https://doi.org/10.1016/j.ehrm.2011.12.001. 
52. You R, Zou X, Hua YJ, Han F, Li L, Zhao C, et al. Salvage endoscopic nasopharyngectomy is superior to intensity-modulated radiation therapy for local recurrence of selected T1-T3 nasopharyngeal carcinoma - a casematched comparison. Radiother Oncol. 2015;115(3):399-406. https://doi. org/10.1016/j.radonc.2015.04.024.

53. Koole SN, van Lieshout C, van Driel WJ, van Schagen E, Sikorska K, Kieffer $J M$, et al. Cost effectiveness of interval cytoreductive surgery with hyperthermic intraperitoneal chemotherapy in stage III ovarian cancer on the basis of a randomized phase III trial. J Clin Oncol. 2019;37(23):2041-50. https://doi.org/10.1200/JCO.19.00594.

54. Zhou Q, Li HL, Gu YT, Li Y, Chen YY, Liu HZ, et al. Economic burden of patients with colorectal cancer and precancerosis in Guangzhou and its influencing factors. China Cancer. 2020;29(1):7-13.

55. Huang HY, Shi JF, Guo LW, Bai YN, Liao XZ, Liu GX, et al. Expenditure and financial burden for the diagnosis and treatment of colorectal cancer in China: a hospital-based, multicenter, cross-sectional survey. Chin J Cancer. 2017:36(1):41. https://doi.org/10.1186/s40880-017-0209-4

56. National Bureau of Statistics of China. China statistical yearbook, 2015, vol. 2020.

57. Eisenhauer EA, Therasse P, Bogaerts J, Schwartz LH, Sargent D, Ford R, et al. New response evaluation criteria in solid tumours: revised RECIST guideline (version 1.1). Eur J Cancer. 2009;45(2):228-47. https://doi.org/10.1016/j.ejca.2 008.10 .026 .

58. Sun Y. Nasopharyngeal carcinoma cohort: posttreatment liquid biopsy surveillance for endemic nasopharyngeal carcinoma: Epstein-Barr virus DNA as a cost effective follow up method. Research Data Deposit https://www.researchdata.org.cn/Search.aspx?Num=RDDA2021001822 (2020).

59. Amin MB, Edge SB, Greene FL, Byrd DR, Brookland RK, Washington MK, et al. AJCC Cancer Staging Manual. 8th ed. New York: Springer International Publishing; 2017. https://doi.org/10.1007/978-3-319-40618-3.

60. ICRU report. Vol. 62: Prescribing, recording, and reporting photon beam therapy. Maryland: International Commission on Radiation Units and Measurements. 1999

61. ICRU report. Vol. 83: Prescribing, recording, and reporting photon-beam intensity-modulated radiation therapy (IMRT). Maryland: International Commission on Radiation Units and Measurements. 2010.

62. Lai SZ, Li WF, Chen L, Luo W, Chen YY, Liu LZ, et al. How does intensitymodulated radiotherapy versus conventional two-dimensional radiotherapy influence the treatment results in nasopharyngeal carcinoma patients? Int J Radiat Oncol Biol Phys. 2011;80(3):661-8. https://doi.org/10.1016/j.jirobp.201 0.03.024.

63. Latimer NR. Survival analysis for economic evaluations alongside clinical trials--extrapolation with patient-level data: inconsistencies, limitations, and a practical guide. Med Decis Making. 2013;33(6):743-54. https://doi.org/1 $0.1177 / 0272989 \times 12472398$

64. Wan $X$, Zhang $Y$, Tan C, Zeng $X$, Peng L. First-line nivolumab plus ipilimumab vs sunitinib for metastatic renal cell carcinoma: a costeffectiveness analysis. JAMA Oncol. 2019;5(4):491-6. https://doi.org/10.1001/ jamaoncol.2018.7086

65. Beck JR, Pauker SG, Gottlieb JE, Klein K, Kassirer JP. A convenient approximation of life expectancy (the "DEALE"). II. Use in medical decision-making. Am J Med. 1982;73(6):889-97. https://doi.org/10.1016/ 0002-9343(82)90787-2.

66. Sathianathen NJ, Konety BR, Alarid-Escudero F, Lawrentschuk N, Bolton DM, Kuntz KM. Cost-effectiveness analysis of active surveillance strategies for men with low-risk prostate cancer. Eur Urol. 2019;75(6):910-7. https://doi org/10.1016/j.eururo.2018.10.055.

67. Lee N, Harris J, Garden AS, Straube W, Glisson B, Xia P, et al. Intensitymodulated radiation therapy with or without chemotherapy for nasopharyngeal carcinoma: radiation therapy oncology group phase II trial 0225. J Clin Oncol. 2009;27(22):3684-90. https://doi.org/10.1200/JCO.2008.19. 9109.

68. Lee NY, Zhang Q, Pfister DG, Kim J, Garden AS, Mechalakos J, et al. Addition of bevacizumab to standard chemoradiation for locoregionally advanced nasopharyngeal carcinoma (RTOG 0615): a phase 2 multiinstitutional trial. Lancet Oncol. 2012;13(2):172-80. https://doi.org/10.101 6/S1470-2045(11)70303-5.

69. Dunsky KA, Wehrmann DJ, Osman MM, Thornberry BM, Varvares MA. PET-CT and the detection of the asymptomatic recurrence or second primary lesions in the treated head and neck cancer patient. Laryngoscope. 2013; 123(9):2161-4. https://doi.org/10.1002/lary.23941
70. Roman BR, Patel SG, Wang MB, Pou AM, Holsinger FC, Myssiorek D, et al. Guideline familiarity predicts variation in self-reported use of routine surveillance PET/CT by physicians who treat head and neck cancer. J Natl Compr Canc Netw. 2015;13(1):69-77. https://doi.org/10. 6004/jncen.2015.0010

71. Cai Z, Chen G, Zeng Y, Dong X, Li Z, Huang Y, et al. Comprehensive liquid profiling of circulating tumor DNA and protein biomarkers in long-term follow-up patients with hepatocellular carcinoma. Clinical Cancer Research. 2019;25(17):5284-94. https://doi.org/10.1158/1078-0432.CCR-18-3477.

72. Roschewski M, Dunleavy K, Pittaluga S, Moorhead M, Pepin F, Kong K, et al. Circulating tumour DNA and CT monitoring in patients with untreated diffuse large B-cell lymphoma: a correlative biomarker study. Lancet Oncol. 2015;16(5):541-9. https://doi.org/10.1016/S1470-2045(15)70106-3.

73. Van Tilborg AA, Bangma CH, Zwarthoff EC. Bladder cancer biomarkers and their role in surveillance and screening. Int J Urol. 2009;16(1):23-30. https:// doi.org/10.1111/j.1442-2042.2008.02174.X.

74. Tang LQ, Lu TY, Li Y, Guo SY, Zhong QY, Zou MS, et al. Patterns of failure and survival trends of 720 patients with stage I nasopharyngeal carcinoma diagnosed from 1990 to 2012: a large-scale retrospective cohort study. J Cancer. 2018;9(7):1308-17. https://doi.org/10.7150/jca.21009.

75. Chua ML, Ong SC, Wee JT, Ng DC, Gao F, Tan TW, et al. Comparison of 4 modalities for distant metastasis staging in endemic nasopharyngeal carcinoma. Head Neck. 2009;31(3):346-54. https://doi.org/10.1002/hed.2 0974.

76. Hong RL, Lin CY, Ting LL, Ko JY, Hsu MM. Comparison of clinical and molecular surveillance in patients with advanced nasopharyngeal carcinoma after primary therapy: the potential role of quantitative analysis of circulating Epstein-Barr virus DNA. Cancer. 2004;100(7):1429-37. https://doi. org/10.1002/cncr.20129.

77. Zhang L, Huang Y, Hong S, Yang Y, Yu G, Jia J, et al. Gemcitabine plus cisplatin versus fluorouracil plus cisplatin in recurrent or metastatic nasopharyngeal carcinoma: a multicentre, randomised, open-label, phase 3 trial. Lancet. 2016;388(10054):1883-92. https://doi.org/10.1016/S0140-6736(1 6)31388-5.

78. Sung H, Ferlay J, Siegel RL, Laversanne M, Soerjomataram I, Jemal A, et al. Global Cancer Statistics 2020: GLOBOCAN estimates of incidence and mortality worldwide for 36 cancers in 185 countries. CA Cancer J Clin. 2021; 71(3):209-49. https://doi.org/10.3322/caac.21660.

79. Wong KCW, Hui EP, Lo K-W, Lam WKJ, Johnson D, Li L, et al. Nasopharyngeal carcinoma: an evolving paradigm. Nature Reviews Clin Oncol. 2021. https://doi.org/10.1038/s41571-021-00524-x.

80. Ferlay J, Ervik M, Lam F, Colombet M, Mery L, Piñeros M, Znaor A, Soerjomataram I, Bray F. Global Cancer Observatory: Cancer Today. International Agency for Research on Cancer, Lyon, France. 2020. https:// gco.iarc.fr/today. Accessed 5 July 2021.

81. Chua MLK, Wee JTS, Hui EP, Chan ATC. Nasopharyngeal carcinoma. Lancet. 2016;387(10022):1012-24. https://doi.org/10.1016/S0140-6736(15)00055-0.

82. Marks JE, Phillips JL, Menck HR. The National Cancer Data Base report on the relationship of race and national origin to the histology of nasopharyngeal carcinoma. Cancer. 1998:83(3):582-8. https://doi.org/10.1 002/(SICl)1097-0142(19980801)83:3<582::AID-CNCR29>3.0.CO;2-R.

83. Pathmanathan R, Prasad U, Chandrika G, Sadler R, Flynn K, Raab-Traub N. Undifferentiated, nonkeratinizing, and squamous cell carcinoma of the nasopharynx. Variants of Epstein-Barr virus-infected neoplasia. Am J Pathol. 1995:146(6):1355-67.

84. McDowell L, Lim A, Corry J. Nasopharyngeal Carcinoma in Nonendemic Populations. In: Raghavan D, Ahluwalia MS, Blanke CD, Brown J, Kim ES, Reaman GH, Sekeres MA, editors. Textbook of Uncommon Cancer. 5th ed. Hoboken: Wiley; 2017. p. 165-95. https://doi.org/10.1002/9781119196235.ch12.

\section{Publisher's Note}

Springer Nature remains neutral with regard to jurisdictional claims in published maps and institutional affiliations. 